\title{
LAS POETAS ESPAÑOLAS CONTRA LA GUERRA DE VIETNAM
}

\author{
JULIO NEIRA JIMÉNEZ \\ UNED \\ jneira@flog.uned.es
}

RESUMEN: Se estudia la abundante participación de las poetas españolas en la antología Con Vietnam, elaborada por Angelina Gatell en 1968 y finalmente prohibida por la censura. La guerra de Vietnam despertó una oleada de protestas en toda la sociedad occidental. Las atrocidades causadas por la maquinaria de guerra norteamericana en la población civil y el medio natural conmovieron la sensibilidad de los poetas españoles, hombres y mujeres, que desde posiciones ideológicas y estéticas muy variadas se unieron en un acto colectivo de protesta que tenía evidentes implicaciones antifranquistas. PALABRAS CLAVE: Guerra de Vietnam, poetas españolas de posguerra, Angelina Gatell, Con Vietnam, lucha poética antifranquista.

* Este artículo se halla vinculado al Proyecto de Investigación del Plan Estatal "Poéticas del 50: proyecciones y diversificaciones", ref. FFI2013-41321-P (AEI/FEDER, UE). 
con frívolos (Marilyn Monroe se codea con Che Guevara, Carlos Marx con Groucho Marx...). De cualquier modo, lo que es claro es su desligamiento de la poesía social, a la que rechazan. ${ }^{1}$

Se trata de una de tantas simplificaciones y verdades a medias en que incurre la historiografía aplicada a la pedagogía, que pretende encajar realidades literarias complejas en esquemas críticos simples. No cabe duda de que muchos de los poetas agrupados en tales etiquetas (Manuel Vázquez Montalbán, José Miguel Ullán, Pere Gimferrer, Antonio Martínez Sarrión, José Ma Álvarez, Leopoldo María Panero, José Infante, el grupo Claraboya - Agustín Delgado, Luis Mateo Díez, José Antonio Llamas-, Cristina Peri Rossi, etc.) escribieron textos que protestaban contra esa guerra o denunciaban su injusticia, la desproporción de las armas empleadas o las atrocidades producidas. Es más, en la famosa antología realizada por Castellet Nueve novísimos poetas españoles (Castellet, 1970), que sirvió de promoción a ese grupo, tres de los poemas seleccionados se referían en mayor o menor medida a ella. Pero el asunto no fue privativo de ellos. En la década de los 60 podemos documentar textos de esa temática en la obra de poetas de todas las promociones desde León Felipe, que superaba los ochenta años y moriría poco tiempo después. Hay composiciones de los poetas nacidos en la última década del siglo XIX y la primera del XX (Jorge Guillén, Gerardo Diego, Vicente Aleixandre, Ángela Figuera, Rafael Alberti); de la siguiente, como Salvador Espriu, Juan Bernier, Celso Emilio Ferreiro, Blas de Otero y Leopoldo de Luis; de los llamados poetas del 50, como José Manuel Caballero Bonald, Ángel González, Alfonso Sastre, José Agustín Goytisolo, Carlos Álvarez, Julio Alfredo Egea, Gloria Fuertes, Gabriel Ferrater, Carlos de la Rica y José Ángel Valente; y de otros más jóvenes, como Francisca Aguirre y Félix Grande. En suma, el motivo interesó y ocupó a buena parte de los poetas españoles de cualquier edad. No se trató de una marca generacional, sino de un signo de la época, transversal a las distintas promociones activas en esa década. estos poetas temas personales (la infancia, el amor...), junto a temas a los que podríamos calificar de «públicos» (la guerra del Vietnam, la sociedad de consumo...); y mezclan tonos graves

${ }^{1}$ En https://docs.google.com/document/d/120BRvB9Ba1xr5dWImziup9JcnJb6Y0_cME9RvUDB6nk/edit?pli=1_[Consultado el 01/08/2015]; párrafo que parece proceder del manual de Lengua Castellana y Literatura de $2^{\circ}$ de Bachillerato, firmado por Vicente Tusón y Fernando Lázaro Carreter, de la Editorial Anaya. 
Dentro de ese conjunto amplio voy a considerar en estas páginas una perspectiva específica: la de las poetas, generalmente relegadas a la invisibilidad por una historiografía literaria tan androcentrista como la nuestra; y un corpus concreto recientemente recuperado: la antología Con Vietnam, elaborada en 1968 por Angelina Gatell, prohibida por la censura gubernativa en 1969, bajo la autoridad del ministro de Información y Turismo Manuel Fraga Iribarne - camuflado como demócrata en la Transición tras la muerte del dictador en 1975- y publicada recientemente (Neira, 2016). Daré algunos datos sobre esta antología. Fue elaborada por encargo del Partido Comunista dentro de la estrategia de "agitación poética" que originó también las antologías España canta a Cuba (AA.VV, 1962)² y Poemas al Che (AA. VV., 1969). ${ }^{3}$ La idea surgió durante el Congreso Cultural celebrado en La Habana del 4 al 11 de enero de 1968, al que asistió una abundante representación de escritores y artistas españoles, entre los que se contaron Gabriel Celaya y Amparo Gascón, José Manuel Caballero Bonald, José Ángel Valente, Luis Goytisolo, Juan García Hortelano, Jaime Gil de Biedma, Félix Grande, Juan Antonio Bardem, Alfonso Sastre y Eva Forest; desde el exilio acudieron Adolfo Sánchez Vázquez, José Bergamín, Jorge Semprún y José Martínez, editor de Ruedo Ibérico.

Al recibir la petición de poemas de Angelina Gatell, Gabriel Celaya contestó el 17 de febrero de 1968: “¿No sabes que, recordando el España canta a Cuba, tengo en proyecto un España canta a Vietnam? Se me ocurrió durante mi estancia en La Habana, y lancé la idea. Tenemos que hablar de esto. Recuérdalo antes de disponer de los poemas que recojas" (Neira, 2016: 17). Pero Angelina Gatell no se amilanó por el tono conminatorio de Celaya y siguió su labor de recogida con entusiasmo. Era la persona

${ }^{2}$ Reúne poemas, entre otros, de Blas de Otero, Rafael Alberti, Carlos Álvarez, Ángel Crespo, Lauro Olmo, Jesús López Pacheco, Ángel González, Carlos Barral, José Agustín Goytisolo, Leopoldo de Luis, José Ángel Valente, Jaime Gil de Biedma, Juan Rejano, Pere Quart, Ángela Figuera y Gabriel Celaya.

${ }^{3}$ Entre los poetas españoles participantes en esta ofrenda lírica destacan Vicente Aleixandre, Victoriano Crémer, Gabriel Celaya, Carlos Bousoño, J. A. Goytisolo, José A. Valente, Rafael Ballesteros, Carlos Sahagún, Manuel Vázquez Montalbán, Antonio Carvajal y José-Miguel Ullán, Celso Emilio Ferreiro, Manuel de Pedrolo y Gabriel Aresti.

UNED. REI, 5 (2017), pp. 123-150 idónea: todos la apreciaban como organizadora con José Hierro, Aurora de Albornoz y José G. Manrique de Lara de la tertulia Plaza Mayor en la librería Abril, foro poético de mucho prestigio entonces; por su lengua materna era de confianza para los poetas catalanes, y colaboraba con Carmen Conde en la elaboración de una antología de poesía femenina (Conde, 1971), por lo que se trataba con las poetas de toda España; además su compromiso político antifranquista desde la adolescencia le acreditaba sobradamente para la tarea. Todos esos rasgos de su perfil se manifiestan en el resultado final: una antología abundante y ecléctica, pues entre los autores reunidos encontramos gran variedad ideológica, temática y formal, con una proporción de mujeres inusualmente alta en las antologías del periodo, sensible también a la presencia de las diferentes lenguas peninsulares.

Asumió el proyecto la editorial Ciencia Nueva, vinculada al PCE, que presentó el original a censura el 14 de septiembre de 1968. El expediente contiene informes de varios censores, cuyas firmas no siempre son reconocibles. Un primer informe, del 8 de octubre, dice:

El libro es todo un muestrario de denuestos contra los americanos, de los horrores de la guerra, tortura, sangre, muerte, melodramas de niños descuartizados, etc. (Cfr. la primera poesía de Alberti). Pero no se hace el menor panegírico del comunismo. En EE.UU. se han publicado críticas tan severas como estas. ¿Vamos a ser nosotros más papistas que el Papa? Se incluyen gráficos poco menos que indescifrables. ${ }^{4}$

Los censores pedían supresiones de versos o de estrofas, pero en general contemplaban la autorización. Sin embargo, la decisión gubernativa fue denegar la publicación el 28 de enero. El motivo es que cuatro días antes el gobierno había decretado el estado de excepción en todo el territorio nacional (Real Decreto 1/1969. BOE, 25/01/69). La situación política venía convulsionándose desde hacía meses por la onda expansiva del Mayo del 68 francés. Se extendían las huelgas y manifestaciones de obreros y estudiantes. Los campus universitarios eran escenarios de escaramuzas

${ }^{4}$ Archivo General de la Administración en Alcalá de Henares. Caja 21/19216; expediente 7620/68.

UNED. REI, 5 (2017), pp. 123-150

ISSN 2340-9029 
con los "grises" diariamente y la represión policial crecía exponencialmente. El detonante final fue la muerte en Madrid el 20 de enero del estudiante de la Universidad Complutense Enrique Ruano, militante del Frente de Liberación Popular, detenido por lanzar en la calle propaganda política y literalmente defenestrado desde un séptimo piso por la policía. El asesinato de Ruano levantó una oleada de protestas y movilizaciones inusitadas y el gobierno temió que se volvieran incontrolables, por lo que decretó el estado de excepción por primera vez en toda España. Una de las primeras consecuencias sería el endurecimiento de la censura de prensa y Con Vietnam se convirtió fue una de sus víctimas.

La labor recolectora de Angelina Gatell se vio muy favorecida por el rechazo unánime de la sociedad española y sus poetas a una guerra sentida como injusta y genocida, que la televisión introducía en los hogares españoles todos los días con imágenes de bombardeos, de pueblos y selvas devastados por el napalm o de matanzas de civiles como la de My Lai, aldea arrasada por las tropas norteamericanas, que violaron a mujeres y niñas y asesinaron a cientos de personas en marzo de 1968. Además, la que comenzó siendo una guerra de independencia de la península Indochina contra Francia, la potencia colonial, tras la II Guerra Mundial, acabó transformándose en un conflicto más de la Guerra Fría, como el de las dos Coreas: el Norte comunista contra el Sur y el neo-imperialismo de los EEUU. En España la guerra de Vietnam tuvo una lectura interna dada la alianza norteamericana con la dictadura de Franco, por lo que el apoyo al Vietcong y el rechazo a la injerencia americana eran una forma más de lucha antifranquista, de manera que se sintieron concernidos los poetas de conocida militancia o colaboración en el ámbito de la izquierda (Alberti, Otero, Celaya, González, Goytisolo, Albornoz, López Pacheco, Caballero Bonald, etc.). Por vía de la empatía solidaria con el sufrimiento de los seres humanos, se solidarizaron otros sin militancia, como Enrique Badosa, los hermanos Murciano, etc., de manera que entre unas y otras causas llegaron a coincidir desde Gerardo Diego hasta Rafael Alberti, por citar a los dos quizás más separados ideológicamente, desde el conservadurismo del santanderino hasta el comunismo del gaditano (Neira, 2001). Angelina Gatell, recientemente fallecida a la edad de noventa años, buscó la colaboración de todos ellos sin distinciones ideológicas o estéticas con el objetivo de que el clamor contra la guerra de Vietnam fuese lo más amplio posible.

Con Vietnam reúne poemas de sesenta y siete autores, de los que catorce son mujeres, cifra bastante más elevada de la habitual en antologías generales, y no es difícil deducir que se debe a que la antóloga fue una mujer. Blas Sánchez Dueñas (2013) ha estudiado la presencia de mujeres en las principales antologías del medio siglo, cuya importancia canonizadora nadie discute, y considera que su escasa representación en ellas es causa principal de la invisibilidad de la mujer en la historiografía sobre la poesía de esa época, lo que no era inaudito, pues lo mismo ocurre respecto a épocas anteriores: ausencia en las antologías, invisibilidad y postergación en el canon. Veamos algunos ejemplos. En la antología Veinte poetas españoles compilada por Rafael Millán (1955) para la colección Ágora solo se incluye una mujer: Ángela Figuera Aymerich. En la de José María Castellet Veinte años de poesía española (1959) solo se incluyeron tres mujeres: Ángela Figuera, María Beneyto y Gloria Fuertes. Luis Jiménez Martos incluyó cuatro autoras en Nuevos poetas españoles (1961): Gloria Fuertes, María Elvira Lacaci, Concha Lagos y Pilar Paz Pasamar. En la segunda edición de su Antología de la nueva poesía española (1964) para Editorial Gredos José Luis Cano incluye sesenta y cuatro nombres, de los que ocho son mujeres: Carmen Conde, Ángela Figuera, Concha Zardoya, Susana March, Gloria Fuertes, María Beneyto, María Elvira Lacaci y Nuria Parés. Leopoldo de Luis en Poesía social (1965) entre los treinta autores totales incluye a Ángela Figuera, Gloria Fuertes, María Beneyto y María Elvira Lacaci. En 1968 José Batlló publicó Antología de la nueva poesía española y sólo Gloria Fuertes le pareció digna de estar entre los diecisiete seleccionados. Las antologías elaboradas en décadas posteriores - con pretendida perspectiva histórica- no mejoran la presencia de mujeres: ni García Hortelano (1978) ni Antonio Hernández (1978) incluyen ninguna, y este anuncia que habrá una antología exclusivamente femenina. Como se aprecia, todos los antólogos habían sido hombres.

Las cartas conservadas por Angelina Gatell nos permiten comprender que pidió a las poetas a la vez textos para esta antología y para la específica que elaboraba con Carmen Conde, pues algunas se refieren a las 
dos en sus respuestas. Estas - como en general todos los epistolarios de escritores - resultan de sumo interés para conocer el "taller" de los textos, las circunstancias de su escritura, las dudas sobre el resultado, y nos permiten contextualizar con mucho detalle el proceso de elaboración de la antología. Por esta razón, incluimos las cartas más significativas en la edición de Con Vietnam y las aprovechamos en las páginas que siguen para conocer mejor la aportación de las poetas. La mayoría de las requeridas aceptó colaborar y envió poemas alusivos, aunque alguna se disculpara por no disponer en ese momento de ningún texto ni de oportunidad para escribirlo. Destaca en ese sentido la respuesta de su gran amiga desde la juventud María Beneyto (Valencia, 1925-2011). Se trataba de una voz reconocida y apreciada en el ámbito de la lírica española. Se había dado a conocer con los libros de poemas Canción olvidada (1947) y Eva en el tiempo (1952) en castellano y Altra veu en catalán en 1953. Durante la década de los 50 obtuvo el Premio Valencia de poesía en 1954 con Criatura múltiple, un accésit del Premio Adonais de 1955 con Tierra viva (1956), un accésit del Premio Boscán con Poemas de la ciudad (1956) y el Premio de poesía catalana Ciutat de Barcelona 1956 con Ratlles a l'aire (1958). Les seguiría Vida anterior (1962) y en 1965 la antología Poesía (1947-1964) publicada por la prestigiosa colección de Plaza y Janés. Pero no pudo ofrecer a Angelina ningún poema. Su carta es muy reveladora de las dificultades de las mujeres en la España de la época para poder dedicarse a la escritura sin las limitaciones que les imponía su condición de mujer que debía ocuparse de la familia:

Valencia, 8 de marzo, 1968

Querida Angelina:

No sabes cómo lamento no poder complacerte en las peticiones que me haces de esos poemas. El problema del Vietnam, como es natural, me escuece, me irrita, pero estoy convencida de que sólo con la indignación no se hacen buenos poemas y yo estoy ahora muy poco propicia a la creación poética. Ya ves, ni siquiera a mi madre le he dedicado los poemas que le debo, cosa bien significativa, conociendo como conoces mi casi idolatría por ella.
Ahora me pillas aturdida, desesperada, Angelina. Incapaz de nada que valga la pena. Atendiendo a un hermano mío - ya sólo me quedan dos- que sufre unas dolencias del todo demenciales y que me lleva de cabeza, con un gasto horroroso - que ojalá sirva para algo- una dedicación constante y el nerviosismo consiguiente por lo grave y difícil del poema. A duras penas atiendo mi colaboración en Levante - ahora hago "El cuento del domingo" - y muy poco más puedo hacer. Es posible que no hiciera este trabajo tampoco de no pagármelo bien y necesitarlo, porque hay veces que me cuesta verdadero esfuerzo atenderlo. Ese es mi panorama.

Para quitarme algo esta obsesión de mi hermano, aguardo con impaciencia el momento de ir a dar dos lecturas a Canarias que me distraerán y que, además están estupendamente compensadas, aparte de viajes y estancia allá. Si paso por Madrid te llamaría. De momento aún no sé las fechas exactas.

Repito mi pena de no poder complacerte. Algo que hice en ese sentido, al principio, se perdió y además era muy malo. Algún día volveré, supongo, a la poesía. (O quizás no, quién sabe).

Un abrazo, y perdona la tardanza a tu amiga María ${ }^{5}$

En el archivo de Angelina Gatell se conservan otras respuestas de poetas que finalmente no aparecerían en la antología. María Eugenia Rincón se disculpa porque no tiene ningún poema del tema solicitado. El caso de Concha Lagos (1907-2007) es distinto, pues envió un poema el 30 de enero de 1968 ("el único donde concretamente nombro al Vietnam”). Mencionaba otro, "Los borrados", publicado recientemente en Poesía española, "que, sin nombrarla, está más directamente relacionado con esa guerra en particular y con todas en general", pero Angelina Gatell debió de considerarlo inadecuado por ese carácter indeterminado y no lo incluyó. Merece la pena señalar que Angelina Gatell se interesó también por la

${ }_{5}^{5}$ Todas las cartas que se reproducen, salvo expresa mención contraria, pertenecen al archivo de Angelina Gatell, que las puso a mi disposición con una generosidad extraordinaria. Agradezco a sus hijos la autorización para citarlas.

UNED. REI, 5 (2017), pp. 123-150

ISSN 2340-9029 
participación de Francisca Aguirre. Sería su marido, Félix Grande, quien la disculpara. El 4 de marzo de 1968 contesta:" En cuanto a Paquita, no ha hecho nada ni creo que pueda por el momento. Empezó a trabajar y ahora ni ella ni yo tenemos tiempo libre para nada" (Neira, 2016: 132). Le sugiere que utilice un poema suyo que ya había publicado en Blanco Spirituals (1967), galardonado en Cuba con el premio Casa de las Américas de 1966, el titulado "Recuerdo de infancia”. Y Francisca Aguirre quedó fuera de la antología. Sin embargo, años después en su poema "La chiquita piconera" del libro Los trescientos escalones mencionará la guerra de Vietnam como uno de los acontecimientos que jalonaron su vida (Aguirre, 2000: 150).

Como ocurre con los poetas varones, también en el caso de las mujeres presentes en esta antología encontramos una gran variedad tipológica. En cuanto a su edad, la mayor de todas es Ángela Figuera Aymerich (1902-1984), coetánea por tanto de Luis Cernuda y Rafael Alberti. Nacidas en la segunda década del siglo, como Blas de Otero, por ejemplo, son Concha de Marco (1916-1989), Gloria Fuertes (1917-1998) Pura Vázquez (1918-2006) y María Luisa Chicote (1920-1989). De la tercera década coincidente con los llamados poetas de los 50, Barral, Valente, Caballero Bonald, etc.- , son la mayoría: Aurora de Albornoz (1926-1990), Angelina Gatell (1926-2017), María de los Reyes Fuentes (1927-2010), María Elvira Lacaci (1928-1997), Elena Andrés (1929-2011), Sabina de la Cruz (1929), Cristina Lacasa (1929-2011). Se trata sin duda del grupo generacional dominante. Las más jóvenes, cronológicamente encuadrables en la generación de 1968, son Josefa Contijoch (1940) y Marta Pessarrodona (1941). Dos son gallegas: María Elvira Lacaci (Ferrol) y Pura Vázquez (Orense), aunque sus poemas están escritos en castellano; cuatro son catalanas: Angelina Gatell (Barcelona), María Luisa Chicote (Barcelona) - aunque ella se consideraba manchega por haber crecido allí (Conde, 1971: 165)—, Josefa Contijoch (Manlleu) y Marta Pessarrodona (Tarrasa), pero solo las dos últimas ofrecen poemas escritos en catalán.

Si atendemos al contenido de sus poemas, la variedad abarca desde la denuncia política (Aurora de Albornoz, Concha de Marco, Angelina Gatell, Josefa Contijoch, Cristina Lacasa, etc.) a la oración religiosa (María Elvira Lacaci, Pura Vázquez), con un amplio espectro de muestras de em- patía con el sufrimiento del pueblo de Vietnam en el resto de autoras, con especial atención a la infancia devastada por la guerra. Algunas muestran preocupación por los efectos medioambientales que producen las armas empleadas, la deforestación de la selva por el napalm, (sobre todo Josefa Contijoch, Angelina Gatell, Ángela Figuera Aymerich), y no falta la denuncia del beneficio económico que obtiene el conglomerado industrialmilitar (Elena Andrés, Cristina Lacasa, Marta Pessarrodona). Algunos poemas hacen expreso su origen en la contemplación de una fotografía de las atrocidades bélicas (Aurora de Albornoz, Ángela Figuera Aymerich, Marta Pessarrodona). También hay heterogeneidad notable en aspectos formales, desde la poesía libre y visual de Josefa Contijoch al isosilabismo heptasilábico de María de los Reyes Fuentes; aunque hay bastante coincidencia en la combinación de versos imparisílabos conocida como silva libre impar. Es general la ausencia de rima. Veamos con cierto detalle los textos de estas poetas que clamaron contra la guerra de Vietnam.

La contribución de Ángela Figuera Aymerich (Bilbao, 1902-Madrid, 1984) es una de las significativas de la antología. En una primera respuesta a Angelina Gatell del 13 de marzo de 1968 se disculpa por su tardanza en contestar y pide más tiempo:

Me interesa mucho figurar en el libro, desde luego. Tengo - tenía- algunos esbozos; pero soy muy mala para improvisar en un momento dado y nada me gusta. Tampoco quiero darte algo que no sea digno no ya de mí sino del Vietnam: una tontería para salir del paso. Ando a vueltas con ello y de tanto que quisiera decir, no alcanzo la precisión, la sobriedad llena de fuego interno que deseo y el tema requiere. Yo escribo mejor mirando hacia atrás, con el tema decantado que en plan choque con las cosas.

En fin, no creas que no quiero mandarte nada. Espera tanto como te sea posible y yo trabajaré. Que no alcanza, mala suerte. (Neira, 2016: 109-110)

Destaca en esta carta su empatía con el tema y el respeto a la propia creación poética: trabajo y reflexión frente a improvisación y efusión 
sentimental, tópicos con que se suele caracterizar la imagen autorial de las mujeres. Para entonces, Ángela Figuera era una mujer muy respetada en la poesía española y era incluida en las principales antologías del momento, pero sus circunstancias personales la habían alejado de la vida literaria. Como se ha dicho ya, había sido la única mujer incluida en la antología compilada por Rafael Millán (1955) y su voz estuvo presente también en la de José María Castellet, Veinte años de poesía española (1959), y en la de Leopoldo de Luis, Poesía social (1965) (Sánchez Dueñas, 2013). Profesora de instituto represaliada tras la guerra por su lealtad republicana, siempre había mantenido su disidencia con el régimen franquista, lo que la vinculaba a poetas "sociales" como Blas de Otero y Gabriel Celaya, pero no frecuentó nunca tertulias ni círculos poéticos. Se había dado a conocer tardíamente, pues publicó su primer libro Mujer de barro (1948) a los cuarenta y seis años. Siguieron Soria pura (1949), Vencida por el ángel (1950), El grito inútil (1952), Los días duros (1953), Víspera de la vida (1953), Belleza cruel (1958) — publicado en México con prólogo de León Felipe-, y Toco la tierra: letanías (1962). Desde 1961 vivía en Avilés, donde su marido era ingeniero de la empresa siderúrgica Ensidesa, y esa distancia de la capital la mantenía aún más alejada de los cenáculos madrileños (González de Langarica / Zabala Aguirre, 2012).

El motivo del retraso con que había recibido la petición de Angelina Gatell era un viaje a Madrid, pero sus viajes no tenían propósito literario, sino eminentemente familiar: "Son tan rápidos que, para el trabajo, son un trastorno, aunque para mi felicidad (por estar con los hijos y la nieta, son un tesoro)". No obstante, apenas quince días más tarde, el 29 de marzo, Ángela Figuera envía su texto para la antología. La carta empieza disculpándose de nuevo porque no ha podido hacerlo antes: "Hemos estado días en Madrid porque operaron inesperadamente a una hermana de mi marido. Salimos de repente. Allí imposible hacer nada" (Neira, 2016: 111). Parece evidente que la actividad creadora de Ángela Figuera se supeditaba por completo a la condición de madre, abuela, esposa, cuñada, etc., lo que era habitual según las pautas sociales en esos años del clericalismo franquista, y ella lo asume sin manifestar ninguna discrepancia. Como venía siendo norma en la sociedad patriarcal española desde hacía siglos, la

actividad literaria de las mujeres era considerada muy secundaria respecto a sus obligaciones familiares, cuando no claramente reprobable.

Ángela Figuera envía una serie de cinco poemas, compuestos en silva libre impar con versos de siete, nueve, once sílabas y alejandrinos, bajo el título "Vietnam. Primeros planos", que remite al ámbito del lenguaje visual. Y en efecto, como si de un documental cinematográfico se tratara, nos presenta los efectos de la guerra sobre "Los viejos", "El arroz", "La selva", "Los niños" y "Las madres", las víctimas más indefensas del conflicto, perspectiva acorde con la mantenida en toda su trayectoria poética de empatía con el sufriente, con el desvalido (Payeras, 2003: 17-60). El primer verso de "Los viejos": "Vemos al yanqui con su presa", que se refuerza en el cuarto ("Le vemos vacilar") y se repite al inicio de la tercera estofa, revela su carácter de écfrasis. Parece guiarnos a través de uno de tantos reportajes televisivos sobre la guerra a que antes nos referimos. Describe sus imágenes, la del anciano que es víctima temblorosa ("No de temor. Su cuerpo se estremece/ de vejez y de ira") y la del victimario que lo apresa ("ese bigboy de metralleta al hombro/ y un rubio cigarrillo entre los labios"), que sin embargo sí tiene miedo porque sabe que en esos cuerpos de apariencia frágil "se oculta un rojo corazón gigante/ con espoleta de odio inextinguible,/ un explosivo extraño y peligroso". Los dos siguientes poemas denuncian la devastación forestal producida por el armamento norteamericano para impedir la alimentación y el cobijo que ofrece la naturaleza a los vietnamitas ("Pero la selva tiene entrañas/ maternales y próvidas/ para los hijos de su tierra / que la conocen y la aman"). En "Los niños" insta a contemplar las imágenes del genocidio infanticida ("Mirad, mirad los niños aplastados,/ acuchillados, rotos, perforados, roídos/ por el napalm; mirad sus carnes puras...") producido por quienes se consideran amorosos padres: ("El yanqui escribe a la familia/ y manda besos a los pequeñines.)". Y, finalmente, el poema "Las madres" exalta la "indomable voluntad de vida" de esas mujeres que "vemos" cargando con los hijos a la espalda, o abrazándolos, protegiéndolos, huyendo de las zonas de combate, preservando ese único bien que poseen y es la esperanza de futuro de su pueblo.

Concha de Marco (Soria, 1916-Madrid, 1989) envió a Angelina Gatell el 1 de febrero de 1968 el poema "Cuaderno de ejercicios", uno de los 
más originales de la antología. También ella era poeta de iniciación tardía. Hasta entonces sólo había publicado Hora 0,5 (1966) y Diario de la mañana (1967), a los que seguirían cinco libros más: Acta de Identificación (1969), Congreso en Maldoror (1970), Tarot (1972), Las Hilanderas (1973) y Una noche de invierno (1974). Y no era el único rasgo que la vinculaba a Ángela Figuera, pues también había sufrido la marginación de los vencidos en la posguerra. Licenciada en Ciencias Naturales por la Universidad Central de Madrid, tuvo que ganarse la vida dando clase en un colegio de Castuera (Badajoz) mientras su marido, el historiador del arte Juan Antonio Gaya Nuño, estuvo preso. Luego, en 1943 le acompañó en su destierro en Bilbao y en sus traslados a Madrid, Barcelona y finalmente Madrid. Como tantas otras mujeres de aquellos años, supeditó su carrera profesional a la de su marido y su labor poética era bastante recóndita (Martínez Laseca, 2016).

“Cuaderno de ejercicios" (Neira, 2016: 157-159), compuesto también en silva libre impar, utiliza el recurso del manuscrito encontrado, en este caso el cuaderno escolar de un niño vietnamita de once años, Dinh Hung, medio roto y con manchas que parecen de sangre, pero podrían ser de tinta roja, para dar voz a las victimas más desvalidas de la guerra. Los cinco versos iniciales y los ocho finales describen el cuaderno y enmarcan las anotaciones que contiene desde el 11 y el 27 de enero. En la parte central del texto leemos en primera persona las tareas escolares ("Estudiamos los verbos auxiliares. / Ejemplos de oración subordinada), las consignas ("El esfuerzo de todos puede ganar la guerra"), los efectos devastadores de los bombardeos sobre la naturaleza ("Las bombas de fósforo destruyen los campos de arroz. / Mueren los peces en el río y flotan [...] El napalm quema todo cuanto toca, / no se puede apagar.").

La guerra lo ocupa todo, la vida (el 19 de enero llega a la escuela una niña nueva a la que enterraron viva y vio morir a su madre decapitada) y los ejercicios escolares, de redacción (“Cómo se enfrentó Huang Van Thu al pelotón de ejecución [...] Ejercicio de redacción. / El perro loco es una granada"), o de matemáticas: calcular el número de cuchillas de acero que tiene cada una de esas granadas. La entrada del 27 de enero es la última. La página contiene el dibujo de un río con una casa, un árbol, pájaros y un sol con rayos y esta nota: "Así será mi casa cuando recuperemos nuestra tie- rra,/ cuando los soldados america.... La palabra truncada es el signo de la muerte del niño, que corroboran los "mil borrones de sangre" del resto de las páginas, de los que nos informa la voz narradora en la estrofa final. Es lógico pensar que un bombardeo ha destruido la escuela, la casa o el poblado entero. Se trata sin duda de un planteamiento muy eficaz en la denuncia de las atrocidades: dar la voz a las víctimas y evidenciar los efectos reales sobre la vida humana que tiene una guerra tan desproporcionada. Similar preocupación por la infancia hemos visto en Ángela Figuera y encontraremos luego en otras autoras, pero no es privativo de las poetas, como demuestran los poemas de José Albi ("Niña y muerte en el Vietnam”), Enrique Badosa ("Canción para despertar a los niños del Vietnam"), Miguel Fernández ("Coplas tristes para el Vietnam”), Joaquim Horta ("Vietnam"), Carlos Murciano ("Epitafio para Wendy Biuh”), José G. Ladrón de Guevara ("Los niños del Vietnam"), Leopoldo de Luis ("Escalada"), Manuel Maria ("Si pensó no Vietnam") o Alfonso Sastre ("Lejano Viet-Nam").

El caso de Gloria Fuertes (Madrid, 1917-1998) es bien distinto. Su trayectoria editorial era ya extensa (Isla ignorada, 1950, Aconsejo beber hilo, 1954, Antología y poemas del suburbio, 1954,...Que estás en la tierra, 1962, Ni tiro, ni veneno, ni navaja, 1965, Cangura para todo, 1967). Ese mismo año publicaría Poeta de guardia, 1968, y uno después Cómo atar los bigotes del tigre, 1969; con Ángela Figuera era la poeta más antologada. De familia proletaria, la suya es una historia de superación personal. Estudió taquigrafía y mecanografía y entre 1939 y 1958 trabajó como secretaria en una fábrica. Estudió biblioteconomía en el Instituto Internacional entre 1955 y 1960, donde empezó a trabajar como bibliotecaria en 1958. Entre 1961 y 1963 disfrutó una beca Fullbright en Estados Unidos, donde impartió clases de literatura española en las universidades de Bucknell, Mary Baldwin y Bryn Mawr. A su regreso impartió clases de español para estudiantes norteamericanos en el Instituto Internacional. En 1972 pudo dedicarse en exclusiva a la literatura gracias a una beca Juan March para literatura infantil (Méndez, 2000).

Aunque desde 1939 había escrito cuentos y poemas para niños como redactora de la revista Maravillas, en 1968 no era asociada exclusivamente con la literatura infantil, como ocurriría a raíz de su trabajo en 
Televisión Española a partir de los años setenta. Se la vinculaba antes con el vanguardismo postista, a través de su amistad con Carlos Edmundo de Ory y su colaboración en las revistas Postismo y La Cerbatana; con la poesía femenina a través del grupo Versos con faldas, que fundó en 1951 con Adelaida Lasantas, dedicado a organizar lecturas en bares y cafés de Madrid; con la revista Arquero, que dirigió entre 1950 y 1951; y con la poesía realista de oposición al Régimen, pues no en vano su libro ...Que estás en la tierra fue publicado en la colección Colliure junto a los de Carlos Barral, Jaime Gil de Biedma, Alfonso Costafreda, José Agustín Goytisolo, Jesús López Pacheco, Caballero Bonald, Gabriel Celaya, Ángel Crespo, Ángel González o José Ángel Valente. Con muchos de ellos, y como única mujer, fue incluida ese mismo año en la Antología de la nueva poesía española de José Batlló, a cuyo cuestionario respondió: “Tengo tanta fe en la nueva -y buena- poesía, que podríamos hacer con ella una nueva religión, y desde ella —desde y con—, la poesía, destruir la injusticia, y el odio —o sea, las guerras-." (Batlló, 1968: 337-338).

Desde esa convicción, Gloria Fuertes envió dos poemas para la antología: "Cuando la tonelada de tierra entierra viva la sonrisa de un niño —que no sabe qué pasa-" y "Extranjero noticias". Angelina Gatell incluyó solo el primero, que abunda en la denuncia del desastre ecológico y el infanticidio, con los juegos de palabras habituales de su poética, rimas ripiosas y paronomasias: "El río Perfume/ ya huele mal,/ no flotan pétalos/ flotan cachos de carne flotan/ de los chicos de la flota/ y de los guerrilleros de la cota”. Y desechó el otro, tal vez por su brevedad, tan característico de su personalidad que parece oportuno recuperarlo ahora:

\section{7-2-68 EXTRANJERO-NOTICIAS}

Yo, la tan pacífica,

estoy impacífica impaciente.

Yo, la $\tan$ tranquila

estoy de sostén de fuerza

de camisa de vietnamita (norte o sur)

ese cristo del siglo XX

muerto por nosotros,

('no amen')

\section{Te lo mandé hace ya tiempo.}

Por Mercedes Saorí sé que estás preparando un libro sobre el Vietnam. Como yo tengo ese poema que te envío, tú verás si te sirve para incluirlo. De paso, te ruego me escribas unas líneas para saber directamente de ti. Yo creo que iré a Madrid en Semana Santa, pero todavía no es seguro. Por si no voy te escribo estas líneas.

También me dice Mercedes que entre Carmen Conde y tú vais a sacar una nueva edición de Antología Viviente. Enhorabuena, mucho me alegra todo lo que sea salir cosas nuevas a la luz del sol. En breve podré mandarte mi libro número 15, ya está para salir.

Y nada más, sino desear verte pronto, y que no me olvidéis, que estoy muy sola por esta inmensa Andalucía...

Con un saludo a tu esposo, recibe un fuerte abrazo de tu amiga. 
Pura

Aunque desde muy joven escribía también en gallego, envió un poema en castellano, "Oración por Vietnam y Vietcong", en efecto, muy apropiado para la antología, que cerraría por el orden alfabético de autores adoptado. Se trata de una plegaria en verso libre que reclama el cese de las atrocidades (“iSeñor! ¿ No hay nada que detenga ese afán de exterminio [...] ¡Señor! Disipa la tiniebla, apaga el sollozo, levántalos" (Neira, 2016: 215-216)), pero también un grito de denuncia de los motivos reales de la intervención militar estadounidense en Vietnam: "el fanatismo alza su bandera de intereses inconfesables [...] esta lucha feroz de ambiciones, la herrumbre del odio despiadado"; y proclama su empatía con los seres que sufren sus terribles efectos: "Allá lejos - pero tan cerca-, Vietnam y Vietcong agonizan [...] de los campos lejanos, encenagados por la guerra,/ de las ciudades destruidas, de los niños hambrientos,/ de las mujeres viudas, de los hombres asesinados".

Apenas tenemos datos de María Luisa Chicote (Barcelona, 1920-Madrid, 1989). Ella misma es muy escueta en la "Noticia bibliográfica" que envió por esas fechas para la antología Poesía femenina española (Conde, 1971: 165): sólo afirma haber cursado Bachillerato superior en el Instituto de Ciudad Real, haberse trasladado a Madrid en 1945, donde se casó y tuvo dos hijas. Habría empezado a escribir en 1960 y sólo había publicado un libro, Jirones (1965), en la que parece una autoedición. En 1970 apareció Esquina doblada en Editora Nacional. María Luisa Chicote envió a Angelina Gatell el poema "Yo pecador" con una carta fechada el 8 de febrero de 1968 en la que mostraba algunos recelos sobre si encajaría en el libro y "aun si será publicable o no". Seguramente sus dudas se referían tanto a la calidad del texto, algo habitual en la mayor parte de las cartas de estas autoras, como a la viabilidad de que superase el filtro de la censura gubernativa. No dejaba de ser razonable su sospecha por tan entusiasta panegírico sobre los soldados vietnamitas:

Diminutos gigantes de marfil escarlata

que sabéis de la pólvora sobre el llanto y el beso.

Guerrilleros del sol.

Hijos de la mañana que os sembráis generosos

abonados con sangre.

A vosotros:

Vietnamitas o mártires con símbolo de estrellas.

[...]

hijos de la quimera (Neira, 2016: 81)

Y por los denuestos con que menciona los Estados Unidos: “imperio/ de tarados y razas que se escuda/ en el símbolo del baldón democracia”, en línea con el poema de Rafael Alberti "Desprecio y maravilla de la Guerra del Vietnam" que abre la antología. Frente a la heroica resistencia del pueblo vietnamita en lucha tan desigual, la poeta se avergüenza de la "pasividad de bueyes", de la comodidad con la que se leen o escuchan las informaciones en la sociedad española, que despiertan sus gritos de furia, asco, pena, y ese despertar de conciencia con que entona su mea culpa.

Con Aurora de Albornoz (Luarca, Asturias, 1926-Madrid, 1990) se inicia la serie de poetas cuya edad corresponde a la llamada Generación del 50. Pertenecía a una conocida familia de intelectuales y escritores republicanos. Su tío abuelo, Álvaro de Albornoz fue ministro de la República y presidente del gobierno en el exilio en París y en México. Su tío, Severo Ochoa de Albornoz, obtuvo el Premio Nobel de Medicina en 1959. Desde 1944 su familia vivía exiliada en Puerto Rico, en cuya Universidad ella estudió bajo el magisterio de Juan Ramón Jiménez. Regresó a España para doctorarse en la Universidad de Salamanca en 1966. Volvió entonces como profesora de la Universidad de Puerto Rico, pero la lejanía de España y de su lucha por la libertad se le hizo insoportable. Volvió definitivamente en 1968 como profesora de la Universidad Autónoma de Madrid y de la Universidad de Nueva York en España. Fue activa militante de Partido Comunista de España en el frente de la cultura. Como filóloga fue muy reconocida su obra crítica sobre poesía española contemporánea: Miguel de Unamuno, Antonio Machado, Juan Ramón Jiménez, José Hierro y el exilio republicano sobre todo. En 1968 había publicado los libros de poesía Brazo de niebla, 1957, Poemas para alcanzar un segundo, 1961, Por la primavera blanca. Fabulaciones, 1962, y En busca de esos niños en hilera, 1967, y hasta su muerte publicaría siete más. 
Aurora de Albornoz hizo llegar a Angelina Gatell el poema "Ante una fotografía" en una carta escrita todavía desde Puerto Rico el 9 de febrero de 1968, en la que le explicaba: "Sobre Viet Nam, te envío este poema inédito (creo que va a ser publicado también aquí y en Cuba). Como ves, Vietnam es aquí más bien un pretexto 'anti-imperialista'. Espero, sin embargo, que te sirva. De todos modos, tengo otros en preparación sobre el mismo tema." No olvidemos que en Puerto Rico hay también un importante sentimiento contra los Estados Unidos que es sentido en muchos ámbitos como potencia colonial, por lo que la empatía con el pueblo vietnamita era tan grande como la de Cuba. Pero como su título expresa, el poema se refiere más a los sentimientos personales de la autora ante la fotografía de un adolescente asesinado en Vietnam que a la guerra misma. Consumiendo esos cigarrillos a los que era tan aficionada, la poeta siente la culpa de quienes viven una vida cómoda, insensible ante el sufrimiento vietnamita:

Hoy quiero confesarme ante este cuerpo.

Culpable de enredar

recuerdo

y sueño

y humo.

Culpable de callar,

y hasta de hablar,

a veces...

Culpable de hacer versos,

mientras hay gentes que asesinan niños

y pretenden vender su mercancía

a niños de otros pueblos

- ¡San Juan de Puerto Rico!-

para que vivan siempre

- ya por siempre-

de no saber,

de no pensar...,

de plazos cómodos.
Angelina Gatell (Barcelona, 1926-Madrid, 2017) se había dado a conocer con Poema del soldado en 1955, libro galardonado con el premio Valencia de poesía, y había publicado Esa oscura palabra en 1963; año en que fue firmante de la carta de ciento tres intelectuales al ministro Fraga en protesta por la represión de los mineros asturianos y de sus mujeres, episodio que la marcó como sospechosa para el Régimen. Antes se ha explicado ya su situación estratégica en la poesía española de 1968. Un año después publicó Las claudicaciones, y en 1971 la primera biografía española de Pablo Neruda; pero luego mantendría un silencio poético de casi cuarenta años, refugiada en la traducción, la literatura infantil y su trabajo como actriz de doblaje, hasta que en los primeros años del siglo XXI la recuperó la editorial Bartleby (Los espacios vacíos y Desde el olvido, 2001, Ceniza en los labios, 2011, La oscura voz del cisne, 2015, En soledad, con ella, 2015). El poema que incluye en su antología es "Vietnam", que expresa en primera persona el dolor que le produce en el desvelo nocturno el sufrimiento del pueblo vietnamita y la destrucción de su tierra, así como su impotencia:

Pero no puedo contestar.

Acaso oyes mi dolor. No sé. Quisiera

con este largo oficio de silencio,

decirte, desgarradoramente,

que estoy contigo, que contigo muero

un poco cada día.

María de los Reyes Fuentes (Sevilla, 1927-2010) era una poeta de corte mucho más tradicional. Desde 1946 era funcionaria del Ayuntamiento de Sevilla, con cuyo patrocinio fundó en 1953 la revista Ixbiliah, que dirigió hasta 1959. También dirigió la revista radiofónica Poesía en Radio Nacional de España en Sevilla. Su vinculación a la cultura de su ciudad fue notable (Círculo Hispalense, Ateneo, Universidad, Club La Rábida, etc.) y promovió numerosas tertulias e iniciativas literarias, que impulsaron la creación poética de los jóvenes que vendrían en denominarse "generación sevillana del cincuenta y tantos" (Jurado Morales, 2016). Se había dado a conocer como poeta a finales de los cincuenta (Actitudes, 1958, De mí hasta el hombre, 1958), pero fue en los sesenta cuando su obra alcanzó el apogeo (Sonetos del corazón adelante, 1960, Elegías del Uad-el-Kebir, 1961, Elegías 
tartessias, 1964, Oración de la verdad, 1965, Acrópolis del testimonio, 1966 Concierto para la Sierra de Ronda, 1966, Pozo de Jacob, 1967). Su contribución a la antología es un breve poema en heptasílabos que ensalza el heroísmo de seres anónimos que luchan por la supervivencia y compara la de Vietnam con la resistencia de los celtíberos de Numancia contra Roma, paradigma español de la dignidad en la defensa de la independencia ante el invasor. Tal pedigrí histórico no le sirvió para evitar que los censores exigieran suprimir la mención a Numancia, como cualquier otra a lugares españoles, obsesionados por borrar cualquier referencia a la realidad española.

La otra gallega presente en la antología es María Elvira Lacaci (Ferrol, 1928-Madrid, 1997). Junto a Ángela Figuera era una de las poetas más significativas de aquellos años. Había sido la primera mujer ganadora del Premio Adonais en 1956 con su libro Humana voz, en cuya colección publicó también Sonido de Dios (1962), y había obtenido el Premio de la Crítica con Al este de la ciudad (1963). Fue incluida en la antología de Luis Jiménez Martos Nuevos poetas españoles (1961) y en la de Leopoldo de Luis Poesía social (1965) (Sánchez Dueñas, 2013). Optó también por una plegaria poética: "Oración por la paz", dentro de la línea de sensibilidad religiosa con que fundió sus preocupaciones sociales, lo que le daba una nota distintiva entre los poetas de esa tendencia reunidos por Leopoldo de Luis, pero contra la tentación de considerar esta temática religiosa como rasgo de "poesía femenina", conviene aducir que también tienen ese carácter el poema de Victoriano Cremer ("Plática anticipada con el niño en Navidad") y la "Pregària pel Vietnam" de Francesc Vallverdú.

También pide la paz para Vietnam Sabina de la Cruz (1929), en el único poema que conocemos de esta profesora de literatura en la Universidad Complutense de Madrid, que aquel año empezó su relación con Blas de Otero, recién llegado de Cuba, con quien se casaría y a quien dedicaría su vida personal y su actividad como filóloga. El breve texto denuncia "con palabras de ira/ a dentelladas" la falacia de la "paz armada, desarmada en Vietnam,/ donde los niños se desangran/ con tu nombre en la frente" (Neira, 2016: 94).

También Elena Andrés (Madrid, 1929-2011) se había doctorado en Filología Románica por la Universidad Complutense y ejercía como profesora de literatura. Hasta entonces había publicado El buscador, 1959, Eterna vela, 1961 y Dos caminos, 1964, que obtuvo un accésit en el Premio Adonais del año anterior. Su poema, "Presencia del Vietnam" (Neira, 2016: 48-51), es una silva libre impar que incide en la denuncia ecologista ante el desastre natural y la infancia destrozada por la guerra, a la que se dirige ("Para ti, sin distancia,/ desde aquella mañana en que una bomba/ te borró padres, casa,/ y te dejó un silencio/ tan ferozmente tuyo en desconcierto"). Tampoco falta la denuncia del capitalismo como motor del imperialismo que arrasa Vietnam ("Impera en estos días/ una raza de duros/ mercaderes tenaces,/ sus leyes están secas,/ sin lógica ni savia; sólo queda/ sobre la inercia astuta/ de viejas estructuras un letrero/ ya frívola etiqueta:/ enmohecidas palabras"). Su mensaje final es de esperanza, de confianza en que crece la muchedumbre que siente "una aguda noción de dignidad/ universal y humana”, que hará ver claro al mundo y detendrá la guerra.

Sobre Cristina Lacasa (Tarrasa, Barcelona, 1929-Lérida, 2011) no existen muchos datos contrastables. Su bibliografía hasta 1968 es: La voz oculta (1953), Los brazos en estela (1958), Un resplandor que perdonó la noche (1961), Con el sudor alzado (1964), accésit del Premio Ágora, y Poemas de la muerte y de la vida (1966), Premio de poesía castellana Ciudad de Barcelona en 1964. Cristina Lacasa respondió con mucha rapidez a la solicitud de Angelina Gatell, como explica en su carta del 2 de febrero de 1968:

Le incluyo con la presente el poema que me pide sobre el Vietnam, o mejor dicho, la guerra del Vietnam. Anteayer recibí su carta y ayer lo escribí. Como me lo pide con rapidez no tengo tiempo para dejarlo reposar... No estoy segura de él en su forma poética, hubiera querido algo mejor. Pero sí me horroriza esa guerra y repudio la actitud americana. O sea, que, aunque no lo había escrito, sí deseaba escribirlo. Y se lo envío.

Como Angelina Gatell le contestó pidiéndole textos para la antología de poesía femenina y tranquilizándole amablemente sobre el poema, al enviarlos ella volvió a disculparse el 8 de febrero con frases de mucho interés para conocer su imagen autorial: 
Te agradezco tu benévola opinión sobre mi poema del Vietnam. Yo no estoy satisfecha. Hubiera querido rehacerlo y trabajarlo más. Pero no había tiempo. Así me pasa siempre. Que he de hacer todo con esa prisa y luego no me gusta y quedo muy insatisfecha, como casi de todo lo que he publicado.

Sin embargo, luego no debió de juzgar mal el poema enviado, una silva libre impar compuesta de heptasílabos, eneasílabos y endecasílabos titulada “¿Dónde tu salvación, Vietnam?”, pues lo recogió en su antología Mientras crecen las aguas (1977). En realidad no difiere en exceso del tono medio del volumen. Denuncia el doble lenguaje norteamericano de bellas palabras ("que muestran sus sonrisas blancas, púdicas, / y hablan de amor, de libertad, de humano/ progreso [...] alzan/ copas de buena voluntad en brindis, bebiéndose tu sangre disfrazada/ con nombres diferentes") y la cosecha mortífera de sus armas con el patetismo de un lenguaje desgarrado, que reproduce imágenes contempladas cotidianamente; eso sí con tendencia a cierta truculencia en la adjetivación ("vísceras sagradas [...] agónicos suspiros [...] gargantas bárbaras [...] invisibles collares de cabezas/ infantiles [...] estoica máscara clavada/ como una cruz ritual sobre el semblante [...] levadura en sortilegio [...] levadura negra [...] delirantes primaveras/ de sangre [...] alas deformes destilando infamia”).

Las otras dos poetas de la antología nacieron en años correspondientes ya a la cronología de la llamada Generación del 68 o grupo de los Novísimos. Se trata de Josefa Contijoch (Manlleu, 1940) y Marta Pessarrodona (Tarrasa,1941). Ambas enviaron poemas escritos en catalán; no olvidemos que esos años fueron los de la explosión del catalanismo cultural (Nova Cançó, etc.) después de décadas de represión franquista de su lengua. Josefa Contijoch, sin embargo, había empezado a escribir en castellano (De la soledad primera, 1964, Aquello que he visto, 1965, Tombstone blues (1967), pero a partir de entonces todos sus libros y novelas lo fueron en catalán. Y este fue el momento de su cambio de idioma. En su carta del 6 de febrero de 1968 cuenta a Angelina Gatell:

Trabajo poemas catalanes, escribo lento, pero voy cogiendo confianza a la lengua, tengo necesidad total de esta expresión.
Voy puliendo en vistas a una edición, que será, posiblemente, pronto. Te diré algo en su día.

Respecto al poema con temática Vietnam, sí tengo algo, pero como es reciente, es catalán, claro. Supongo no interesa.

Pero se equivocaba, sí interesaba, y lo envía el 18 de febrero después de corregirlo, con la habitual incertidumbre del creador ante el resultado final ("En fin, ahora mismo -después de corregir y trabajar estas palabras- no sé decirte si merece la pena. Tú veras.”); y con algunas advertencias curiosas: "Otra cosa: de publicarse, cuida que conserven la forma, es muy importante (el cajista o linotipista se va a cagar con esta Contijoch del diablo). En fin, paciencia”. Era más que justificada la advertencia porque se trataba de un texto muy al día, de la entonces llamada por unos poesía experimental, por otros poesía visual, que encomendaba a sucesivos sangrados en la página la secuenciación del verso. Por si acaso, Angelina Gatell le envió una traducción hecha por ella para que la autora diera su parecer. Esta dio el visto bueno el 29 de febrero con una nota en la que insistía: "Yo no sé en realidad si este 'romanço' vale la pena de tanto follón. Tú puedes verlo más claro”. En nuestra edición hemos reproducido el texto original en catalán y la traducción de Angelina Gatell en nota al pie. Se trata de un canto a los jóvenes guerrilleros vietnamitas muertos en plena juventud, antes casi de que pudieran gozar del amor, en una lucha desigual contra el invasor.

Marta Pessarrodona era una joven poeta aún inédita, aunque ese mismo año 1968 publicaría Primers dies de 1968. Angelina Gatell no conservó ninguna carta suya, sólo el original mecanografiado de su poema "VIETNAM-ALWAYS", manuscritos su nombre y la fecha "Primavera 1967”, lo que quiere decir que no era fruto de la petición de la antóloga. Este es otro texto que parte de la contemplación de una fotografía, la de los campos de arroz arrasados por los bombardeos; denuncia el servilismo de la técnica a esa maquinaria de destrucción e incide en la impotencia del escritor para detener con palabras tanta barbarie: "Els camps romandran 
erms i els mots/ no seran un fertilitzant suficient"; ${ }^{6}$ una perspectiva similar a la del poema de Ángel González.

La consideración global de estas aportaciones de las mujeres a la antología Con Vietnam permite concluir que, con la salvedad ya explicada de María Beneyto y Concha Lagos, Angelina Gatell logró reunir a las más significativas poetas del momento, e incluyó con generosidad a otras menos relevantes, que, sin embargo, sumaban en la tarea de despertar conciencias y crear el clima de repulsa generalizada ante una guerra tan cruel, desproporcionada y mortífera. No se trataba de seleccionar calidad literaria, sino de añadir voluntad antibelicista desde la sensibilidad creadora de las mujeres. No otra cosa hizo respecto a los poetas varones. Hay grandes figuras, pero también autores de segundo o tercer nivel. Tampoco los textos de las mujeres desentonan del nivel medio de los hombres: ni se diferencian notablemente en la temática o la forma. En unas y otros hay composiciones de tono religioso; unas y otros se posicionan con claridad en pro del bando más débil y denuncian el carácter genocida de la guerra, su barbarie, la destrucción de la naturaleza, los efectos terribles sobre la población civil, niños, mujeres, ancianos; unas y otros denuncian el carácter mercantil del imperialismo estadounidense; unas y otros emplean una gran variedad formal, inclinadas ellas más a la ausencia de esquemas métricos clásicos.

En suma, no encontramos rasgos definitorios que pudieran tipificar como "femenina" la poesía de las autoras incluidas en esta antología. Hay una misma rabia, una misma sensación de impotencia, un mismo clamor que los de los poetas contra la guerra de Vietnam. Y similares respuestas poéticas. Y ello es relevante en unos años sobre los que la historiografía y la crítica han venido cerrando los ojos a la existencia de un número bastante considerable de autoras. En ocasiones simplemente con el silencio, que les ha conducido a la invisibilidad total, en otras con la etiqueta "femenina” que connotaba por sí sola consideración peyorativa. En todo caso, es momento de acabar con esa postergación. Entre unas y otros hay excelen-

6 "Los campos permanecerán yermos y las palabras/ no serán fertilizante suficiente". Traducción de Angelina Gatell. tes, buenos y malos poetas. Juzguemos la poesía de las mujeres por sus valores intrínsecos, por su capacidad para producir una emoción artística en nuestra experiencia lectora. Como cualquier otro texto. Pero estudiémosla desde parámetros específicos, distintos a aquellos que han establecido los críticos para la fijación del canon de una poesía casi exclusivamente masculina; y hagámoslo teniendo en cuenta su contexto real, las circunstancias y los condicionamientos familiares y sociales en que hubieron de desarrollar su creación, solo de esa manera será ecuánime su valoración.

Recibido: 29/3/2017

Aceptado: 7/5/2017

\section{Referencias bibliográficas}

AA.VV. (1962), España canta a Cuba, París: Ruedo Ibérico.

- (1969), Poemas al Che, La Habana: Instituto Cubano del Libro (facsímil Barcelona: Los libros de la Frontera José Batlló, 1976 y 1978).

Aguirre, Francisca (2000), Ensayo general. Poesía completa (1966-2000), Madrid: Calambur.

Batlló, José (1968), Antología de la nueva poesía española, Madrid: Ciencia Nueva.

Cano, José Luis, ed. (1958), Antología de la nueva poesía española, Madrid: Gredos .

Castellet, José María, ed. (1960), Veinte años de poesía española (19391959), Barcelona: Seix Barral.

Castellet, José María (1970), Nueve novísimos poetas españoles, Barcelona: Barral.

Conde, Carmen (1971), Poesía femenina española (1950-1960), Barcelona: Bruguera.

Fuertes, Gloria (1968), Poeta de guardia, Madrid: Ciencia Nueva, Colección El Bardo. 
García Hortelano, Juan (1978), El grupo poético de los años 50, Madrid: Taurus.

González de Langarica, Pablo y José Ramón Zabala Aguirre (2012), Ángela Figuera Aymerich. Poesía entre la sombra y el barro, Bilbao: Muelle de Uribitarte.

Hernández, Antonio (1978), Una promoción desheredada; la poética del 50, Madrid: Zero-Zix.

Jiménez Martos, Luis, ed. (1961) Nuevos poetas españoles, Madrid: Ágora. Jurado Morales, José (2016), “La trayectoria poética de María de los Reyes Fuentes: una escritora de la 'generación sevillana del cincuenta y tantos", Prosemas. Revista de Estudios Poéticos, 2, pp. 157-181.

Lanz, Juan José (2011), Nuevos y novísimos poetas en la estela del 68, Sevilla: Renacimiento.

Luis, Leopoldo de, ed. (1965), Poesía social, Madrid: Alfaguara.

Martínez Laseca, José María (2016), Concha de Marco en carne y verso, Soria: Ayuntamiento de Soria.

Méndez, Pablo (2000), Lo que aprendí de Gloria Fuertes, Madrid: Nostrum. Millán, Rafael, ed. (1955), Veinte poetas españoles, Madrid: Ágora.

Neira, Julio (2001), "Rafael Alberti y Gerardo Diego: confluencias y divergencia en la poesía española (1925-1936)", Boletín de la Biblioteca Menéndez Pelayo, 77, pp. 35-62.

- ed. (2016), Con Vietnam, selección y prólogo de Angelina Gatell, introducción de Julio Neira, Madrid: Visor.

Payeras, María (2003), El linaje de Eva. Tres escritoras españolas de posguerra: Ángela Figuera, Celia Viñas y Gloria Fuertes, Madrid: SIAL Ediciones.

Sánchez Dueñas, Blas (2013), "Voces poéticas de mujer en la órbita de las antologías conformadoras de la Generación del 50", en María Payeras Grau ed., Desde las orillas. Poetas del 50 en los márgenes del canon, Sevilla: Renacimiento, pp. 229-250. 